\title{
Impact of deferring intravitreal antiangiogenic in patients with diabetic macular edema or secondary to central retinal vein occlusion during the COVID-19 pandemic
}

\section{Impacto de diferir antiangiogénicos intravítreos en pacientes con edema macular diabético o secundario a obstrucción venosa central de la retina durante la pandemia de COVID-19}

\author{
Jibran Mohamed-Noriega*, Abraham Olvera-Barrios, and Karim Mohamed-Noriega \\ Department of Ophthalmology, Faculty of Medicine, University Hospital, Universidad Autónoma de Nuevo León, NL, Mexico
}

\section{Dear editor,}

The coronavirus disease 2019 (COVID-19) pandemic has forced us to change the way we practice ophthalmology. At the beginning of the pandemic and in search of some guidance on how to act, general recommendations were outlined on what was believed to be more or less urgent. More than 6 months after the first case was diagnosed in Mexico, it is important to reflect on the impact of deferring care in some patients.

In the Department of Ophthalmology of the University Hospital and Faculty of Medicine of the Universidad Autónoma de Nuevo León, in each new case of neovascular glaucoma (NVG), we carry out a careful and systematic evaluation of the factors that caused the progression of this disease that is potentially preventable. Since we began to register the causes of NVG, and unlike in many countries, every year we have found diabetic retinopathy (DR) as the first cause. However, in the last month, this has changed.

During July 2020, seven new patients with NVG came to our institution, one caused by DR and six by central retinal vein occlusion (CRVO). When evaluating the reason for this change in the cause of NVG, we realized that these patients were under ophthalmological monitoring and their follow-up appointments or the application of intravitreal antiangiogenic was deferred. This practice, which at the beginning of the pandemic was considered safe and was even published in this journal ${ }^{1}$, should be reconsidered. The recommendation published in May-June 2020 suggested the following management of intravitreal injections:

"Diabetic macular edema/macular edema secondary to venous occlusions: Unlike eyes with wet AMD, in eyes with diabetic macular edema or retinal vein occlusion, postponement of the injection generally does not jeopardize the visual prognosis, and can be compensated by resuming injections."

The unexpected number of patients with NVG associated with CRVO in the last month occurred in patients actively treated by ophthalmologists, who managed macular edema with antiangiogenic. This treatment meant that the patients never developed anterior segment or retinal neovascularization and were not treated with panretinal photocoagulation (PP). As a consequence of delayed treatment and prolonged follow-up visit intervals in cases without PP, these patients progressed to NVG (also known as 3-month glaucoma) after a few months.

\section{Correspondence:}

*Jibran Mohamed-Noriega

Av. Madero y Gonzalitos, s/n

Col. Mitras Centro

Date of reception: 05-09-2020

C.P. 64460 , Monterrey, N.L., Mexico

E-mail: jibran.mohamednrg @uanl.edu.mx
Available online: 11-01-2021 Rev Mex Oftalmol (Eng). 2021;95(1):42-43 www.rmo.com.mx 2604-1731/○ 2020 Sociedad Mexicana de Oftalmología. Published by Permanyer. This is an open access article under the CC BY-NC-ND license (http://creativecommons.org/licenses/by-nc-nd/4.0/). 
After clinical studies, such as protocol $\mathrm{I}^{2}$, protocol $\mathrm{S}^{3}$, or $\mathrm{BRAVO}^{4}$, the treatment of macular edema with a high ischemic component (DR and CRVO) has changed from using a laser as first-line treatment to using intravitreal antiangiogenic routinely. Without a doubt, this change has brought important benefits. However, given the COVID-19 pandemic and the limitation of health services, we must emphasize some aspects with our patients. It should be noted that when deciding to opt for antiangiogenic in cases without PP, additional time should be spent in the office to educate the patient and explain the serious risk they have of evolving to NVG if treatment is deferred.

Based on this experience, we recommend that all cases with diabetic macular edema or macular edema secondary to CRVO without previous PP, continue with the intravitreal antiangiogenic regimen as planned, be closely monitored, or undergo PP as soon as possible. If it is decided to defer intravitreal antiangiogenic, we suggest close monitoring at intervals of no more than
3 months, a reasonable period according to the time in which most of our patients evolved to NVG.

\section{Conflicts of interest}

The authors declare no conflicts of interest.

\section{References}

1. Olivares-de Emparan JP, Garza-Leon M, García-Aguirre G, Azcárate-Coral T. Recomendaciones para el manejo de pacientes que requieren atención oftalmológica durante la pandemia de SARS-CoV-2 Recommendations for the management of patients that require eye care during the SARS-CoV-2 pandemic. Oftalm. 2020;94(3):103-12.

2. Elman MJ, Aiello LP, Beck RW, Bressler NM, Bressler SB, Edwards AR, et al. Randomized trial evaluating ranibizumab plus prompt or deferred laser or triamcinolone plus prompt laser for diabetic macular edema. Ophthalmology. 2010;117(6):1064-77.e35.

3. Sun JK, Glassman AR, Beaulieu WT, Stockdale CR, Bressler NM, Flaxel C, et al. Rationale and Application of the Protocol S Anti-Vascular Endothelial Growth Factor Algorithm for Proliferative Diabetic Retinopathy. Ophthalmology. 2019;126(1):87-95.

4. Campochiaro PA, Heier JS, Feiner L, Gray S, Saroj N, Rundle AC, et al. Ranibizumab for macular edema following branch retinal vein occlusion: six-month primary end point results of a phase III study. Ophthalmology. 2010;117(6):1102-12.e1. 